\title{
PENGARUH LATIHAN PADA DYSMENORRHEA
}

\author{
Srimiyati \\ Fakultas Ilmu Kesehatan UKMC \\ Email: srimiyati@ukmc.ac.id
}

\begin{abstract}
ABSTRAK
Latar Belakang: Nyeri menstruasi terjadi pada otot sekitar rongga panggul. Otot menjadi kejang, tegang dan nyeri punggung. Menurut Benson \& Pernoll, (2009) sebagian besar wanita mengalami nyeri menstruasi ringan, sepertiga mengalami nyeri sedang, dan sebagian kecil merasakan nyeri hebat. Senam merupakan salah satu teknik relaksasi yang dapat digunakan untuk mengurangi nyeri, karena saat melakukan senam, otak dan susunan saraf tulang belakang akan menghasilkan endorphin, hormon yang berfungsi sebagai obat penenang alami dan menimbulkan rasa nyaman.Tujuan: Untuk mengetahui pengaruh senam dysmenorrhea terhadap nyeri haid.

Metode: penelitian ini adalah quasi eksperimental, bentuknya pre-exsperimental design, dengan rancangan one group pre test- post test tanpa kelompok kontrol. Jumlah responden 52 orang, dipilih dengan cara purposive sampling. Pengumpulan data dilakukan 2 kali yaitu sebelum dan sesudah perlakuan. Responden diberi perlakuan 4 kali. Analisis data menggunakan Kolmogorov-smirnov dan uji Wilcoxon. dengan tingkat kemaknaan 0,05 . Hasil penelitian menunjukkan nilai p $0,001(<0,005)$ artinya ada hubungan antara senam dismenorea terhadap nyeri haid. Senam efektif untuk mengurangi nyeri haid. Dianjurkan bagi wanita dengan dismenore untuk melakukan senam ini, agar nyeri haid bisa berkurang, dan insidens dismenore dapat diturunkan.
\end{abstract}

Keywords: nyeri haid; senam dismenore

THE EFFECT OF EXERCISES ON DYSMENORRHEA

\begin{abstract}
Background: Menstrual pain occurs in the muscles around the pelvic cavity causing muscles to become seizures, tension and back pain. Benson \& Pernoll (2009) said that 50\% of women experience mild menstrual pain 30\% moderate pain and $10 \%$ severe pain. Gymnastics is one of the relaxation techniques that can be used to reduce pain because while doing gymnastics, brain and spinal cord will produce endorphins, a hormone that serves as a natural sedative and create a sense of comfort. Objevtive: To know the effect of dysmenorrhea gymnastics to menstrual pain on Female Student Faculty of Health Sciences University Katolik Musi Charitas Palembang 2017. Method: this research is quasi experimental, the form is pre-experimental design, with the design of one group pre test-post test without control group. The number of respondents was 52 people, selected by purposive sampling. Data collection was done twice, before and after treatment. Respondents were treated 4 times. Analysis data using Kolmogorov-smirnov and Wilcoxon test with a level significance of 0.05 . The results showed $p$ value : $0.001(<0.005)$ meaning that there was a relationship between dysmenorrhoeal exercise and menstrual pain. Gymnastics is effective for reducing menstrual pain. It is advisable for women with dysmenorrhea to do this gymnastics, so that menstrual pain can be reduced, and the incidence of dysmenorrhea may decrease.
\end{abstract}

Keywords : dysmenorrhea, gymnastics dysmenorhea

Jurnal SMART Keperawatan Sekolah Tinggi Ilmu Kesehatan (STIKes) Karya Husada Semarang www.stikesyahoedsmg.ac.id/ojs/index.php/sjkp(perawat) 


\section{Pendahuluan}

Menstruasi merupakan peluruhan dinding uterus yang disebut endometrium (Irianto, 2014). Perdarahan fisiologis secara periodik dari uterus yang terjadi khusus pada wanita. Haid sebagai proses katabolisme dibawah pengaruh hormon hipofisis dan ovarium (Benson \& Pernoll, 2009). Menstruasi umumnya dimulai saat wanita memasuki masa pubertas, yang menggambarkan bahwa sistem reproduksi wanita sudah matur.

Nyeri haid merupakan sensasi tidak nyaman pada perut bagian bawah sebelum dan selama menstruasi disertai mual. Karakteristik nyeri sangat khas, terjadi secara reguler dan periodik menyertai menstruasi. Beberapa wanita sering merasakan nyeri pada perut bagian bawah, punggung bagian bawah, pinggang otot paha hingga betis (Wiknjosastro, 2008). Sekalipun nyeri haid dapat menghilang dengan sendirinya akan tetapi sering mengganggu aktivitas dan memerlukan istirahat beberapa jam sampai satu hari. Sensasi ketidaknyamanan apabila tidak segera diatasi akan berpengaruh pada fungsi mental dan fisik.

Senam dysmenorrhea diyakini sebagai salah satu cara mengurangi nyeri haid. Gerakan dalam senam akan merangsang otak dan saraf tulang belakang menghasilkan hormon endorphin yang berfungsi sebagai obat penenang alami dan menimbulkan rasa nyaman (Haruyama, 2011). Mengacu pada penelitian Ulfa (2015) bahwa senam dysmenorrhea mampu mengurangi nyeri haid. Responden sebelum melakukan senam memiliki intensitas nyeri sedang sebesar 57,14\%, setelah melakukan senam berubah menjadi 39,28\%.

Berdasarkan survey awal pada mahasiswi Fakultas Ilmu Kesehatan dari 20 mahasiswi terdapat 15 (75\%) diantaranya mengalami dismenore saat menstruasi. Sensasi nyeri haid yang dirasakan menurunkan konsentrasi dan tidak termotivasi mengikuti kuliah bahkan terpaksa meninggalkan perkuliahan karena tidak tahan merasakan nyeri haid. Tingginya prevalensi dismenore yang dialami mahasiswi dan mengganggu aktivitas kuliah peneliti tertarik melakukan penelitian tentang pengaruh senam Dysmenorrhea terhadap nyeri haid di Fakultas Ilmu Kesehatan Unika Musi Charitas Palembang. 


\section{Tinjauan Teoritis}

Dismenore merupakan gangguan yang sering dialami hanya oleh wanita remaja post pubertas (Edmons, 2007). Nyeri haid disebabkan oleh adanya gangguan organ reproduksi atau faktor hormonal dan bukan karena faktor psikologis semata (Benson \& Pernoll, 2009). Hormon Prostaglandin memicu terjadinya kontraksi uterus untuk mendorong keluar darah haid (Chandran, 2008). Kadar prostaglandin meningkat selama fase luteal sehingga kontraksi uterus menjadi lebih sering, tidak terkoordinasi. Akibat peningkatan kontraksi uterus ini aliran darah berkurang dan menimbulkan iskemia atau hipoksia uterus yang menyebabkan nyeri (Reeder \& Griffin, 2011).

Menurut French, (2005) dismenore diduga akibat pengeluaran prostaglandin darah dan menyebabkan kontraksi uterus dan nyeri. Nyeri haid (dismenore) yang dialami remaja umumnya dismenore primer yaitu nyeri haid yang terjadi beberapa tahun pertama setelah menarche (Proverawati \& Misaroh, 2009). Sebanyak 90\% dari remaja wanita di seluruh dunia mengalami masalah saat haid dan lebih dari 50\% dari wanita haid mengalami dismenore primer (Berkly, 2013). Dismenore primer terjadi setelah 1-2 tahun menstruasi pertama. Sensasi nyeri haid yang dirasakan membuat konsentrasi menurun (Ju, Hong et all, 2013), tidak termotivasi mengikuti kuliah bahkan terpaksa meninggalkan perkuliahan karena tidak tahan merasakan nyeri haid (Parker, 2010). Sumber lain mengatakan 2-3 tahun setelah wanita mengalami menarche pada usia antara 12-15 tahun (Kasdu, 2005). Berdasarkan hal tersebut dismenore dialami oleh remaja di awal usia 20-an dan akan menurun seiring tambahnya usia (Anurogo, 2008).

Prevalensi dismenore di Indonesia sebesar 64,25\% yang terdiri dari 54,89\% dismenore primer dan dismenore primer dialami oleh $60-75 \%$ remaja. Nyeri haid ini tidak membahayakan tetapi dapat mengganggu dan mengurangi produtivitas wanita. Menurut Ningsih (2012) remaja wanita yang mengalami dismenore, 7-15\% tidak pergi ke sekolah. Ketidaknyamanan yang dirasakan seperti: kram pada perut bagian bawah, mual sampai muntah, kembung, pusing, mudah marah. Gejala ini muncul sebelum haid dan belangsung sampai 2 hari. 
Upaya mengurangi dampak dismenore yang merugikan para wanita, perlu tindakan yang mudah dilakukan mandiri, dimana dan kapan pun. Dalam keperawatan upaya mengatasi nyeri haid melalui pengembangan terapi non farmakologi yaitu teknik relaksasi. Terapi relaksasi memungkinkan individu melakukan kontrol diri ketika muncul rasa nyeri dan dapat digunakan baik dalam keadaan sehat maupun sakit (Perry \& Potter, 2010). Senam merupakan salah satu teknik relaksasi yang dapat mengurangi nyeri menstruasi. Gerakan-gerakan senam menstimulasi otak dan susunan syaraf tulang belakang memproduksi hormon endorphine. Hormon ini memiliki peran sebagai penghilang rasa sakit alami, dan menimbulkan rasa nyaman (Harry, 2007).

Senam dysmenorrhea merupakan aktivitas fisik yang digunakan untuk mengurangi nyeri. Apabila melakukan senam secara teratur, tubuh terstimulasi memproduksi hormon endorpin. Hormon endorpin yang cukup dapat memberikan energi positip dan menurunkan nyeri serta melancarkan pengiriman oksigen ke otot yang membuat seseorang akan menjadi rileks dan lebih nyaman (Sugani \& Priandarini, 2010).

\section{Metode Penelitian}

Penelitian ini dilakukan di Unika Musi Charitas Palembang, pada bulan Januari - April 2017. Jenisnya penelitian ini adalah quasi eksperimental design bentuknya pre-exsperimental design, dengan rancangan one group pre test- post test. Tujuannya untuk mengetahui pengaruh senam dysmenorrhea terhadap nyeri haid, subyek penelitian ini mahasiswi. Pengambilan sampel menggunakan cara purposive sampling, jumlah sampel 52 responden. Pengambilan data dilakukan 2 kali, untuk mengukur perubahan nyeri sebelum dan sesudah diberi perlakuan senam dismenore. Perlakuan diberikan sebanyak 4 kali. Pengumpulan data menggunakan alat ukur Numeric Rating Scale (NRS). Analisis data menggunakan uji Wilcoxon karena sebaran data distribusinya tidak normal. 


\section{Hasil Penelitian}

Tabel 1. Distribusi Derajat Nyeri Sebelum dan Sesudah Senam Dismenore $(n=58)$

\begin{tabular}{lcccc}
\hline \multirow{2}{*}{$\begin{array}{c}\text { Derajat } \\
\text { Nyeri haid }\end{array}$} & \multicolumn{2}{c}{ Sebelum Perlakuan } & \multicolumn{2}{c}{ Sesudah } \\
\cline { 2 - 5 } & Frequency & Persent & Frequency & Percent \\
\hline Tanpa Nyeri & 0 & 0 & 2 & $3.40 \%$ \\
\hline Nyeri Ringan & 3 & $5.20 \%$ & 38 & $65.50 \%$ \\
Nyeri Sedang & 39 & $67.20 \%$ & 18 & $31.00 \%$ \\
Nyeri Berat & 16 & $27.6 \%$ & 0 & $0 \%$ \\
\hline Total & $\mathbf{5 8}$ & $\mathbf{1 0 0}$ & $\mathbf{5 8}$ & $\mathbf{1 0 0} \%$ \\
\hline Sumber: Srimiyati $(2017)$ & & & &
\end{tabular}

Hasil penelitian menunjukkan bahwa sebelum diberi intervensi terdapat sebanyak 16 $(30,8 \%)$ mengalami nyeri berat, $33(63,5 \%)$ nyeri sedang, dan $3(5,8 \%)$ nyeri ringan. Sedangkan setelah diberi perlakuan senam dismenore sebanyak 4 kali didapatkan ada 2 $(3.40 \%)$ tidak mengalami nyeri, $38(65.50 \%)$ nyeri sedang, 18 (31\%) nyeri ringan. (Tabel.1).

Tabel 2 Gambaran Nyeri Haid Sebelum dan Sedudah Senam Dismenore $(n=58)$

\begin{tabular}{ccccc}
\hline Variabel & Mean & Median & Min-Max & SD \\
\hline Sebelum intervensi & 5.52 & 5.00 & $2-9$ & 1.478 \\
Sesudah intervensi & 3.22 & 3.00 & $0-6$ & 1.590
\end{tabular}

Sumber: Srimiyati (2017)

Nilai rata-rata nyeri haid sebelum senam dismenore adalah 5.52, dan rata- rata nyeri sesudah senam sebesar 3,22. Perbedaan nyeri haid sebelum dan sesudah senam sebesar 2.29, dengan $p$ value 0,001 (CI 95\%: 2.01- 2.57), (Tabel. 2).

Tabel 3 Beda Rerata Nyeri Haid Sebelum dan Setelah Senam Dismenore $(\mathbf{n}=58)$

\begin{tabular}{lcccc}
\hline \multicolumn{1}{c}{ Nyeri haid } & Rata-rata (s.b) & $\begin{array}{c}\text { Beda rata-rata } \\
(\mathbf{s . b})\end{array}$ & IK 95\% & P.Value \\
\hline Sebelum Senam & $5.52(1.47)$ & $2.29(1.07)$ & $2.01-2.57$ & $\left.<0.001^{*}\right)$ \\
Sesudah Senam & $3.22(1.59)$ & & & $*$ Uji paired T-test
\end{tabular}


Hasil uji beda mean berdasarkan uji paired sample t-test pada signifikansi $95 \%$ didapatkan nilai $\mathrm{p}=0.000$, dan nilai mean 2.29, dengan simpangan baku 1.07.

Tabel 4 Pengaruh Senam Dismenore Terhadap Nyeri Haid $(\mathbf{n}=58)$

\begin{tabular}{lccc}
\hline \multicolumn{1}{c}{ Nyeri haid } & $\begin{array}{c}\text { Median } \\
(\text { Min-Max) }\end{array}$ & p. value & $\mathbf{Z}$ \\
\hline Nyeri dismenore sebelum senam $(\mathrm{n}=58)$ & $5.00(2-9)$ & $\left.0.001^{*}\right)$ & $\left.7.156^{*}\right)$ \\
Nyeri dismenore setelah senam $(\mathrm{n}=58)$ & $3.00(0-6)$ & & \\
\hline Uji Wilcoxon, 47 responden nyeri dismenore berkurang dan 5 responden nyeri dismenore tetap \\
\hline \multicolumn{4}{l}{} \\
Sumber: Srimiyati (2017)
\end{tabular}

Berdasarkan analisis Uji Wilcoxon didapatkan nilai $\mathrm{Z}$ hitung sebesar 7.156 ( $\mathrm{Z}_{\text {hitung }}$ lebih besar dari $\quad Z_{\text {tabel }}=1.96$ ) artinya ada perbedaan signifikan nyeri dismenore responden antara sebelum senam dismenore dengan sesudah senam dismenore. Dari 58 responden terdapat 47 yang mengalami penurunan nyeri setelah senam dismenore dan 5 responden nyeri haid menetap (Tabel. 3).

\section{Pembahasan}

a. Penurunan Nyeri Sesudah Perlakuan

Hasil penelitian menunjukkan sebagian besar responden mengalami nyeri haid berat sebelum diberikan dengan skor nyeri rata-rata 5.52. Setelah diberi perlakuan senam dismenore sebanyak 4 kali skor nyeri haid rata-rata 3,22. Hasil penelitian ini mendukung penelitian Daley (2008) yang menyatakan olahraga efektif dalam menurunkan nyeri haid primer. Peneliti lain yang terkait adalah penelitian Suparto (2009) senam dismenore efektif mengurangi nyeri haid pada remaja putri $(\mathrm{p}=0.000)$. Gerakan senam dysmenorrhea dirasakan dapat mengurangi nyeri haid setelah dilakukan secara rutin sebanyak 4 kali dalam seminggu, dengan durasi 30 - 45 menit, dilakukan s atu minggu sebelum menstruasi (Haryono, 2016). Gerakan pada senam juga dapat menguatkan otot dasar panggul yang menyangga uterus, vesca urinaia dan rektum agar berfungsi maksimal (Ratna, 2015). 
Nyeri haid ada kaitannya dengan prostaglandin endometrial dan leukotrien (Ismarozi, et al, 2015). Nyeri haid primer yang dirasakan responden karena peningkatan prostaglandin pada endometrium yang mengalami peningkatan setelah ovulasi. Prostaglandin menyebabkan kontraksi myometrium dan mengakibatkan iskemik pembuluh darah sehingga menimbulkan rasa nyeri (Morgan \& Hamilton, 2009). Vasopressin juga berperan meningkatkan vasokonstriksi dan kontraktilitas uterus yang menyebabkan nyeri iskemik. Menurut Edmundson (2007) peningkatan vasopresin terjadi pada wanita dengan dismenore primer. Proverawati \& Misaroh (2009) berpendapat bahwa nyeri haid disebabkan oleh ketidakseimbangan hormon progesteron dalam darah.

Berdasarkan hasil penelitian, setelah dilakukan intervensi senam dismenore didapatkan bahwa nyeri haid mengalami penurunan. Penurunan nyeri haid pada responden karena dengan olah badan atau aktivitas fisik membuat otot menjadi rileks, kekuatan otot meningkat, aliran darah sekitar rongga panggul menjadi lancar. Senam dismenore dilakukan secara sistematis mulai dari gerakan pemanasan, inti, dan pendinginan sehingga benar-benar memberi dampak yaitu melemaskan dan meregangkan otot rahim yang mengalami kontraksi menjelang dan atau selama haid.

b. Pengaruh Senam Dismenore Terhadap Nyeri Haid

Berdasarkan hasil penelitian sebagian besar responden mengalami penurunan nyeri haid setelah senam dismenore. Analisis uji statistik Wilcoxon didapatkan ada perbedaan signifikan nyeri dismenore responden antara sebelum senam dismenore dengan sesudah senam dismenore $\left(Z_{\text {hitung }}>1.96\right)$ pada signifikansi 95\%. Penelitian ini sejalan dengan penelitian Pertiwi, et al (2015), bahwa senam aerobik low impact berpengaruh terhadap dysmenorrhea primer $(p<0.05)$. Menurut Haryono (2016) Senam dysmenorrhea merupakan aktivitas fisik dapat mengurangi nyeri, gerakan pada senam tubuh akan menghasilkan hormon endorphin yang menimbulkan rasa nyaman sehingga dapat mengurangi nyeri. Hormon endorphin merupakan gabungan dari endogenous dan morphine, hormon ini diproduksi oleh kelenjar pituitari (Panjalu, 2014). Hormon endorphin merupakan unsur protein diproduksi oleh sel-sel sistem saraf dalam tubuh 
tepatnya di spinal cord dan ujung saraf (Yesie. A, 2010). Reseptor analgesik ini bekerja sebagai reseptor sedativa untuk mengurangi rasa sakit.

Peneliti berasumsi bahwa nyeri haid yang dialami responden mengalami penurunan setelah diberikan senam dysmenorrhea disebabkan karena gerakan senam yang diberikan sebanyak 4 kali menjelang menstruasi dengan durasi selama 30 menit, gerakan-gerakan tersebut mampu meregangkan, melemaskan otot rahim. Di samping itu ketika responden melakukan aktivitas/senam otak dan saraf tulang belakang tubuh terstimulasi mengeluarkan hormon endorphin yang memberikan rasa nyaman serta dapat menurunkan nyeri. Keteraturan melakukan senam/olahraga maka akan merangsang kadar b-endorphin dengan baik. Ketika seseorang melakukan olahraga/senam, maka b-endorphin akan diproduksi dan ditangkap oleh reseptor di dalam hipothalamus dan sistem limbik yang berfungsi untuk mengatur emosi. Peningkatan b-endorphin berhubungan erat dengan penurunan rasa nyeri, tubuh dapat menciptakan perasaan nyaman dan enak, sehingga rasa nyeri yang dirasakan akan berkurang.

\section{Kesimpulan}

Senam dismenore memberikan pengaruh yang signifikan terhadap penurunan nyeri haid setelah dilakukan senam sebanyak 4 kali di Fakultas Ilmu Kesehatan Universitas Katolik Musi Charitas Palembang dengan ( $p$-value $)$ sebesar 0.000 atau $\left(\mathrm{Z}_{\text {hitung }}\right.$ lebih besar dari $\left.\mathrm{Z}_{\text {tabel }}\right)$

\section{Saran}

Senam dismenore dapat dijadikan pola hidup dan dilakukan secara rutin untuk meningkatkan life expectancy pada penderita nyeri haid. Penelitian selanjutnya dapat melanjutkan penelitian dengan menambah jumlah sampel, jumlah perlakuan serta observasi lebih maksimal.

\section{Daftar Pustaka}

Jurnal SMART Keperawatan Sekolah Tinggi Ilmu Kesehatan (STIKes) Karya Husada Semarang www.stikesyahoedsmg.ac.id/ojs/index.php/sjkp(perawat) 
Aprilia Yesie., 2010. Hipnostetri. Jakarta: Gagas Media

Anurogo. (2008). Segala sesuatu tentang nyeri haid. Diakses tanggal 8 Oktober 2014 dari http://www.kabarindonesia.com/berita.php?pil=3\&dn20080 61916480

Ary Panjalu. (2014). Hypnosexology. Yogyakarta: Galang Pustaka

Aprilia Yesie. (2010). Hipnostetri. Jakarta: Gagas Media

Benson, R. C., \& Pernoll, M. L. (2009). Buku Saku Obsterti \& Ginekologi (9 ed.). Jakarta: EGC.

Berkley KJ. (2013). Primary dysmenorrhea: an urgent mandate. International Association for the Study of Pain. XXI (3): 1-8. October 2013. Accessed on 3 Feb 2016 from https://s3.amazonaws.com/rdcmsiasp/files/production/public/Content/ContentFolders/Publications2/PainClinicalUpdates/ Archives/PCU_21-3_Web.pdf

Chandran, Lahta, (2008). Menstruation Disorders: Overview. E-medicine Obstetrics and Gynecology. Accessed on 21 January 2016 from: http://emedicine.medscape.com/article/953945-overview/

Daley, A J. (2008) . Exercise and primary dysmenorrhea : A comprehensive and critical review of the literature. Sport medicine : Adis data international, 38 (8), 659-670. Accessed on 12 January 2016 from http://web.ebscohost.com/ehost/pdfviewer/pdfviewer ?sid=61f2dladb3f49-.

Edmonds, K. (2007) . Gynaecological disorders of childhood and adolescense : Dewhurst's textbookof obstetrics and gynaecologica 17 th Edition. Blackwell Publishing : London

French, L. (2005). Dysmenorrhea. American Family Phicisian: Academic Research Library. Dari http://proquest.umi.com/pqdweb?index=90\&did=785908271\&SrchMode $=1$

Harry. (2007). Mekanisme endorphin dalam tubuh. Diakses 20 April 2016 dari http:/klikharry.files.com/2007/02/1/ doc+endophin+dalam+ tubuh.

Haruyama, S. (2011). The Miracle of Endorphin. Bandung: Qanita.

Haryono, R. (2016). Siap menghadapi Menstruasi \& Menopause. Yogyakarta: Gosyen Publishing.

Irianto, 2014. Biologi Reproduksi. Bandung: ALFABETA.

Ismarozi, D., Utami, S., \& Novayelinda, R. (2015). Efektifitas Senam Disminorea Terhadap Penanganan Nyeri Haid Primer pada Remaja. Journal Majority, 2 ( 1): 821-825.

Ju H, Jones M, Mishra G. (2013). The prevalence and risk of dysmenorrhea. Oxford University Press. 2013; 36(1):104-13. Accessed on 12 January 2016 from: http://epirev.oxfordjournals.org/

Kasdu, D. (2005). Solusi problem wanita dewasa. Jakarta: Puspa Swara.

Morgan, Geri , Corole Hamilton. (2009) . Obstetri \& ginekologi panduan praktik. Jakarta : EGC.

Ningsih R. (2012). Efektivitas paket pereda terhadap intensitas nyeri pada remaja dengan dismenore di SMAN kecamatan curup. Tesis. Program Pasca Sarjana Universitas Indonesia. Jakarta.

Parker MA, Sneddon AE, Arbon P. (2010). The menstrual disorder of teenagers (MDOT) study : determining typical menstrual patterns and menstrual disturbance in a large population based study of Australian teenagers. BJOG. 1(17):185-92.

Jurnal SMART Keperawatan Sekolah Tinggi Ilmu Kesehatan (STIKes) Karya Husada Semarang www.stikesyahoedsmg.ac.id/ojs/index.php/sjkp(perawat) 
Pertiwi, M. R., Wahid, A., \& Marlinda, E. (2015). Senam Aerobik Low Impact Terhadap Disminore Primer Pada Remaja Putri di SMKN 1 Martapura. Jurnal Dunia Keperawatan, 3(2), 46-52.

Potter, A, P., Perry, \& G, A. (2010). Fundamental Keperawatan (7 ed., Vol. 3). Jakarta: Salemba Medika.

Proverawati Atikah dan Siti Misaroh (2009). bMenarche Menstruasi Pertama Penuh Makna. Yogyakarta: Nuha Medika.

Ratna, L. (2015). Senam Kecantikan. Yogyakarta: FlashBooks.

Reeder, S., Leonide, L., \& Griffin, D. K. (2011). Keperawatan Maternitas Kesehatan Wanita, Bayi, dan keluarga (Vol. 2). Jakarta: EGC.

Sugani, \& Priandarini. (2010). Cara Cerdas untuk Sehat: Rahasia Hidup Sehat Tanpa Dokter. Jakarta: Transmedia.

Suparto, A. (2009). Efektivitas senam dismenoredalam mengurangi dismenore pada remaja $\begin{array}{lllllll}\text { putri. Accessed on } & 10 & \text { Feb } & 2016 & \text { from } & \text { http:// }\end{array}$ penjaskesrek.fkip.uns.ac.id/wpcontent/uploads/2012/04/ultimate.pdf.

Ulfa, T. F. (2015). Pengaruh Senam Disminorea Terhadap Skala Nyeri Disminorea pada Remaja Putri di SMP ALI MAKSUM Yogyakarta. dari http://opac.say.ac.id/775/1/NASKAH\%20PUBLIKASI.pdf

Wiknjosastro.H . (2008). Ilmu kandungan. Jakarta: Yayasan bina pustaka. 